\title{
Influence of Quantum Dot Surface on Electrochemical DNA Sensing Mechanism
}

\author{
Xolile Fuku, ${ }^{*[a, b]}$ Priscilla Baker, ${ }^{[a]}$ and Emmanuel Iwuoha ${ }^{[a]}$
}

Owing to their high surface-to-volume ratio, electrocatalytic activity, biocompatibility and novel electron transport properties, quantum dots (QDs) are highly attractive materials for the ultrasensitive detection of biological macromolecules via bioelectronic devices. In this study, a QD-based genosensor was developed, in which $\mathrm{Ga}_{2} \mathrm{Te}_{3}$-based QDs were synthesized using an aqueous solution approach by mixing 3-mercaptosuccinic acid (3MSA)-capped gallium metal precursor with reduced tellurium metal. The results enabled us to reach an original understanding related to the active material involved in the probe DNA sensing mechanism. The morphological and structural characterization of the QDs was performed prior to their utilization in a DNA sensor construction. High-resolution TEM
(HR-TEM) and atomic force microscopy (AFM) images confirmed the spherical and crystalline nature of the QDs, whereas X-ray photoelectron spectroscopy (XPS) and X-ray diffraction (XRD) analyses were able to confirm the oxidation states and formation of the prepared QDs. UV/Vis was capable of finding the optical band gap energy and the photostability of the QDs. The resultant $\mathrm{Ga}_{2} \mathrm{Te}_{3}$ QDs together with metal ions confirmed their use for DNA signal detection through their DNA binding mechanism in the genosensor construction. Genosensing in $\mathrm{Cs}^{+}$ and $\mathrm{Li}^{+}$ions exhibited high sensitivity $\left(2.74-3.69 \mu \mathrm{Ang}{ }^{-1} \mathrm{~mL}\right.$ ) and very low detection limits $\left(0.4 \mathrm{pg} \mathrm{mL}^{-1}\right)$ with a linear dynamic range of $0.1-1 \mathrm{ng} \mathrm{mL}^{-1}$.

\section{Introduction}

The electrochemical genosensor technological developments together with nanoscience have become one of the most exciting areas in the scientific community, with experimental developments being driven by pressing demands for new technological applications. The development of efficient electrochemical genosensor for sensitive and specific detection of biomolecules is vital to both fundamental biomedical research and clinical diagnosis. Because of their superior properties such as sharper density of states than higher-dimensional structures i.e. bulk, quantum wells and quantum wires, ${ }^{[1]}$ superior transport and optical properties, ${ }^{[2,3]}$ unusually high surface to volume ratios, ${ }^{[4]}$ narrow and size-tunable emission spectrum, versatile surface modification, continuous absorption spectra and distinctive electrochemical activity, ${ }^{[5-7]}$ zero dimensional QD has been regarded as an advantageous and promising alternative for efficient genosensors development with high sensitivity, good specificity and simplicity. This means the surface of QD can be easily modified with an array of sensing elements such as DNAs, peptides, and antibodies to construct the useful QDlabelled probes/ sensors. The sensor basically consists of QD immobilized by a linker to an electrode, so that when excited a

[a] Dr. X. Fuku, P. Baker, E. Iwuoha

SensorLab, Department of Chemistry

University of the Western Cape

Private Bag X17, Bellville 7535, Cape Town, South Africa

[b] Dr. X. Fuku

Energy Centre

Council for Scientific and Industrial Research (CSIR)

P.O. Box 395, Pretoria 0001, South Africa

E-mail:xfuku@csir.co.za

Supporting information for this article is available on the WWW under https://doi.org/10.1002/celc.201902079 signal current is generated which depends on the type of analyte in the immediate environment of the electrode. ${ }^{[8-10]}$ Though the QD-based electrochemical sensors become known later than other optical biosensors, their rapid developed has been encouraged by their high sensitivity without the involvement of expensive instruments. ${ }^{[8-10]}$ In this account, novel biocompatible and water soluble gallium telluride quantum dots $\left(3 \mathrm{MSA}-\mathrm{Ga}_{2} \mathrm{Te}_{3}\right.$ ) will be synthesized and characterized with the aim of demonstrating QD that can be employed for various applications (e.g., bio-imaging, in-vivo, biosensors) and that will be less toxic to humans and the environment. ${ }^{[1]}$ Therefore, Deoxyribonucleic acid (DNA) which is the genetic information carrier of living organisms has been incorporated in construction towards the development of QD-DNA signal-detection mechanism. DNA is employed as a conjugate in this study due to its potential in chemistry, physics, material science, energy, and more specifically genosensing. ${ }^{[12,13]}$ The wide applications are attributable to the versatile functionalities of DNA which includes molecular recognition, catalysis and constructing nanostructures. ${ }^{[14,15]}$ Due to reason unknown, there is a notable scarcity and poor basic understanding of how QDs surfaces influence the DNA hybridization and signaling process in bio/ genosensing. Thus, since the interaction between nano-QD and DNA plays an important role in the bio/genosensing, it is crucial to characterise the nano-QD/ssDNA interactions and explore the underlying chemical mechanisms. In their paper, $\mathrm{Li}$ and coworker, ${ }^{[16]}$ demonstrated QD binding to DNA in which a singlemolecule imaging technique based on atomic force microscopy (AFM) was employed to probe the NPs-DNA interactions with quantum dot (QD) as model NPs. Finally, the fine conformation of QD-DNA binding sites was examined to analyze the binding mechanisms. Meanwhile, Li et al., ${ }^{[17]}$ reported a mechanistic investigation of DNA-mediated morphological evolution of gold 
nanoprism seeds into nonagon, hexagon, and six-pointed stars, in the presence of homo-oligomeric T30, G20, C30, and $A 30,{ }^{[18]}$ while Bonham and others demonstrated the detection of Sequence-Specific Protein-DNA interactions via Surface Enhanced Resonance Raman Scattering and Probing the in vitro mechanism of action of cationic lipid/DNA lipoplexes at a nanometric scale. ${ }^{[19]}$

The study reports the design of sensitive, selective and efficient electrochemical genosensor for the Her2 oncogene. Furthermore, we provide new insights on the developments in the fabrication method and sensing concept concerning direct surface interaction of the analyte-DNA with QD modified electrode. Finally, this work demonstrates for the first time an experimental approach based on electrochemical techniques coupled with metal ion exchange to probe the binding activity and detection signal of nano-QD with ssDNA. We further, explore and address the effect of ions to the binding mechanism between nano-QD and ssDNA. The focuses of these studies is not entirely on the electrochemical signal detection hybridization but also on understanding the interaction/binding of NPs with different types of DNAs.

\section{Experimental Section}

\section{Reagents and Materials}

Gallium metal (Ga, 99.99\%), tellurium powder (Te, 99.99\%), trisodium citrate dihydrate $\left(\mathrm{C}_{6} \mathrm{H}_{5} \mathrm{Na}_{3} \mathrm{O}_{7} .2 \mathrm{H}_{2} \mathrm{O}, 99.3 \%\right)$, sodium tellurite $\left(\mathrm{Na}_{2} \mathrm{TeO}_{3}, 99 \%\right)$, sodium borohydride $\left(\mathrm{NaBH}_{4}, 99.99 \%\right)$, mercaptosuccinic acid (MSA, $99.0 \%)$, acetone (99.8\%). Sodium acetate $(99 \%)$, lithium chloride, cesium chloride, potassium chloride, sodium chloride and phosphate buffered saline tablets. Three electrodes were used for electrochemical measurements i.e., Silver/silver chloride (Ag/AgCl-reference), Pt wire (counter) and working (GCE) electrodes. All materials were purchased from Sigma-Aldrich. 18-21 base oligonucleotide DNA sequences were purchased from Inqaba Biotechnical Industries (Pty) Ltd., Hatfield, South Africa and Eurogentec S.A, Rue du Bois Saint Jean, 5, 4102 Seraing, Dublin). Base sequences: Amine terminated DNA with the sequence NH2-5'-AAT TCC AGT GGC CAT CAA-3', was used as the probe ssDNA. Target DNA (complementary): 5'-GAA CAT GAA GGA CCG GTG GGC-3', - a section of ERF gene of HER-2/neu. The oligonucleotide DNA stock solutions were prepared using phosphate buffer and stored in a freezer at $\left(-20^{\circ} \mathrm{C}\right)$. Phosphate buffer solution (PBS), $0.1 \mathrm{M}, \mathrm{pH} 7.4$ was prepared from anhydrous potassium hydrogen phosphate $\left(\mathrm{K}_{2} \mathrm{HPO}_{4}\right)$ and potassium dihydrogen phosphate $\left(\mathrm{KH}_{2} \mathrm{PO}_{4}\right)$. Deionized water (18.2 M $\Omega$ ) purified by a Millipore system (Synergy) was used for aqueous solution preparations.

\section{Instrumentation}

All electrochemical measurements employed a $\mathrm{CH}$ Instruments Inc $\mathrm{CH} 1630 \mathrm{C}$ potentiostat. Spectroscopic assays were made on transparent flat bottom 96 well plates (FL medical) using a Biotek synergy H1 Hybrid Reader. Fourier Transform Infrared Spectroscopy (FTIR) experiments were performed on a Perkin Elmer spectrometer (Spectrum Model No 100), contact angle measurements were performed on drop sensor analyzer (DSA100, made in Germany). UV-vis spectroscopy was performed on (Nicolet Evolution Model No 100, thermo Electron, made in UK). Microscopic measurements were performed by using high resolution transmission electron microscopy (HR-TEM, Tecnai Model No G2 F20X-Twin MAT 200 kV, made in Netherlands), atomic force microscopy (AFM, Nanosurf easyScan2 Model No, made in Japan). Raman spectra were obtained on (Horiba scientific, Olympus Model No BX41TF MAT 200 kV, made in Japan).

\section{One-Pot Synthesis of $\mathrm{Ga}_{2} \mathrm{Te}_{3}$ Capped with 3-Mercaptosuccinic} Acid

MSA-capped $\mathrm{Ga}_{2} \mathrm{Te}_{3}$ QD was synthesized via two modified procedures according to the previous report. ${ }^{[20,21]}$ Typically, gallium perchloride solution $\left(\mathrm{Ga}\left(\mathrm{ClO}_{4}\right)_{3} .6 \mathrm{H}_{2} \mathrm{O}, 0.04 \mathrm{M}, 4 \mathrm{~mL}\right)$ was diluted to $50 \mathrm{~mL}$ in a one neck flask, tri-sodium citrate dihydrate $(400 \mathrm{mg})$, sodium tellurite $\left(\mathrm{Na}_{2} \mathrm{TeO}_{3} 0.01 \mathrm{M}, 4 \mathrm{~mL}\right)$, mercaptosuccinic acid (MSA, $100 \mathrm{mg})$ and sodium borohydride $\left(\mathrm{NaBH}_{4}, 50 \mathrm{mg}\right)$ were added under vigorous stirring. When the solution became green, the flask was attached to a condenser and refluxed at $100^{\circ} \mathrm{C}$ for the desired period of time $(2 \mathrm{~h})$ under $\mathrm{N}_{2}$ flow. An equal volume of acetone was added to the QD aqueous solution and the precipitated QD was collected via centrifugation (145 rpm, $20 \mathrm{~min}$ ). After decanting the supernatant, the QD was dispersed in PBS and re-precipitated in ethanol. The same procedure was repeated 3 times to thoroughly wash away the free ions. The QD was finally dispersed in Milli-Q water for further analysis, Figure S1.

\section{Preparation of $\mathrm{GCE} / \mathrm{Ga}_{2} \mathrm{Te}_{3}-\mathrm{MSA}$ and $\mathrm{GCE} / \mathrm{Ga}_{2} \mathrm{Te}_{3}-\mathrm{MSA} / \mathrm{dsDNA}$ Electrodes}

Gold $(\mathrm{Au})$ and glassy carbon (GCE) electrodes were thoroughly cleaned by polishing them on a soft polishing pad using 1.00, 0.30 and $0.05 \mu \mathrm{M}$ slurries of alumina, respectively, while rinsing with deionized water after each polish. This was followed by ultrasonication in de-ionized water for $5 \mathrm{~min}$. The electrodes were drop-coated with $3 \mathrm{MSA}-\mathrm{Ga}_{2} \mathrm{Te}_{3}$ solution for $12 \mathrm{~h}$ and left to dry in air/oven to form $\mathrm{Au} / 3 \mathrm{MSA}-\mathrm{Ga}_{2} \mathrm{Te}_{3}$. The modified electrodes were then removed from the $3 \mathrm{MSA}-\mathrm{Ga}_{2} \mathrm{Te}_{3}$ solution and gently rinsed with de-ionized water to remove any physically or weakly adsorbed nanocrystals. The electrode was then immersed in a mixture of phosphate buffer $(\mathrm{pH} 7.40)$ solution of $0.2 \mathrm{M}$ for electrochemical analyses. Different scan rates of $5,10,15,20,25,30 \mathrm{mV} \mathrm{s}^{-1}$ were carried out on the modified electrodes. Gold and carbon screen printed electrode (SPE) were also used in our study for comparison.

\section{Results and Discussion}

\subsection{Band Gap Energy and Quantum Yield of $3 \mathrm{MSA}-\mathrm{GA}_{2} \mathrm{Te}_{3}$ Quantum Dots}

Figure 1 shows the Ultraviolet-visible (UV/Vis) absorption spectra of colloidal $3 \mathrm{MSA}-\mathrm{GA}_{2} \mathrm{Te}_{3}$ quantum dots with average particle sizes of $20 \pm 2 \mathrm{~nm}$. Figure 1 depicts two pronounce absorption peaks at about 220 ( $2 \mathrm{~h}$ before reflux) and $\lambda_{\max }$ at $256 \mathrm{~nm}$ ( $8 \mathrm{~h}$ after reflux), respectively. Further, a shoulder was observed at $\lambda_{\max } 332 \mathrm{~nm}$ which was denoted to 3MSA before reflux. The results suggest that $3 \mathrm{MSA}-\mathrm{GA}_{2} \mathrm{Te}_{3} \mathrm{QD}$ was formed after interaction with the $3 \mathrm{MSA}$, apparent by color change (dark brown to green) and shift in $\lambda_{\max }$. From the observed spectra, an increase in peak intensities was evident with slight shifts $(36 \mathrm{~nm}$ ) in absorption maxima (from higher to lower wavelengths). The shifts and high absorptions in electronic and 


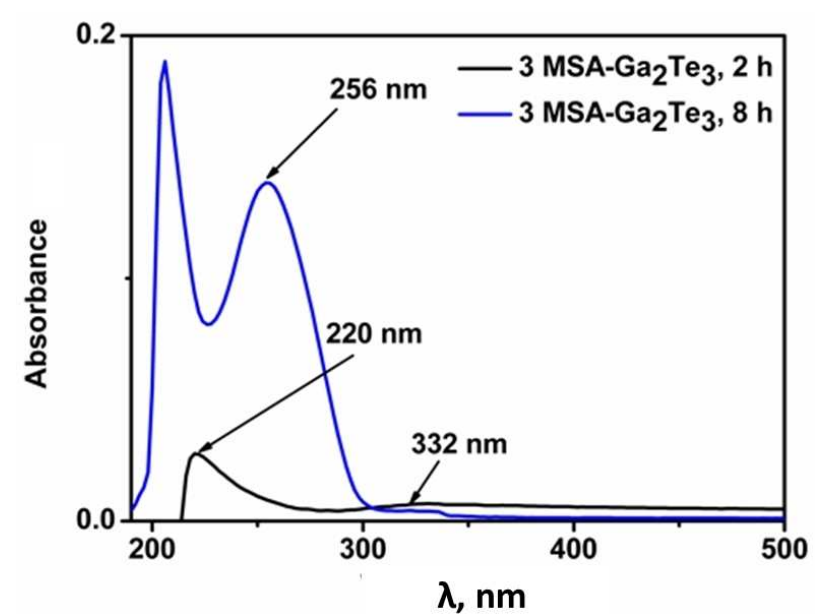

Figure 1. UV/Vis spectra of $3 \mathrm{MSA}-\mathrm{Ga}_{2} \mathrm{Te}_{3}$ quantum dots.

optical properties can be viewed as a function of QD size, morphology shape and crystallinity.

The band gap energies of the prepared QD was calculated using the Planck's equation [Eq. (1)]:

$E_{g}=\frac{h c}{\lambda_{g}}$

where, $E_{g}$ is the band gap energy, $h$ is the Planck constant $\left(6.626 \times 10^{-34} \mathrm{~J} \mathrm{~s}\right.$ or $\left.4.136 \times 10^{-15} \mathrm{eV} \mathrm{s}\right), c$ is the speed of light $=$ $3.0 \times 10^{8} \mathrm{~m} \mathrm{~s}^{-1}, \lambda_{\mathrm{g}}$ is the wavelength maxima of the NPs (220 and $256 \mathrm{~nm}$ ). The calculated band gap energies of the QD at different temperatures were calculated to be $E_{g}=4.1 \mathrm{eV}$ at $(2 \mathrm{~h}$, before reflux) and $E_{g}=3.6 \mathrm{eV}(8 \mathrm{~h}$, after reflux). The results show smaller band gap energies after refluxing, suggesting a good crystallinity of the nanomaterials. Further, the results prove the semiconductive nature of the prepared nano-dot.

Ultraviolet-visible and photoluminescence (PL) spectrometer were employed to study the photophysical properties of rhodamine 6G (with known quantum yield 0.95) and 3MSA$\mathrm{Ga}_{2} \mathrm{Te}_{3}$ quantum dot (Figure 2). The aim of the study was to compare the conventional method with the modern method. The absorbance and the fluorescent intensities of the assynthesized nanodots and rhodamine $6 \mathrm{G}$ are as shown in Figure $2 \mathrm{~A}$ and $\mathrm{B}$. Both rhodamine and $3 \mathrm{MSA}-\mathrm{Ga}_{2} \mathrm{Te}_{3}$ exhibited weak UV/Vis absorption peak at 257 and $527 \mathrm{~nm}$, respectively. The quantum yield of the conventional-dye and the nanodots was calculated (as previously reported form literature) ${ }^{[22]}$ from both the UV/Vis absorption peak and Fluorescent emission peak intensities. There are different equations that are been used in calculating the quantum yield i.e. a single or comparative way. In this study a comparative alternative was used. Fluorescent molecules commonly used as probes in microscopy have quantum yields ranging from very low $(<0.05)$ to near unity. Whereas, higher quantum yields are desirable in most imaging applications.

The quantum yield of the $3 \mathrm{MSA}-\mathrm{Ga}_{2} \mathrm{Te}_{3}$ quantum dot $(0.90)$, which was used as an imaging probe, was higher than that of
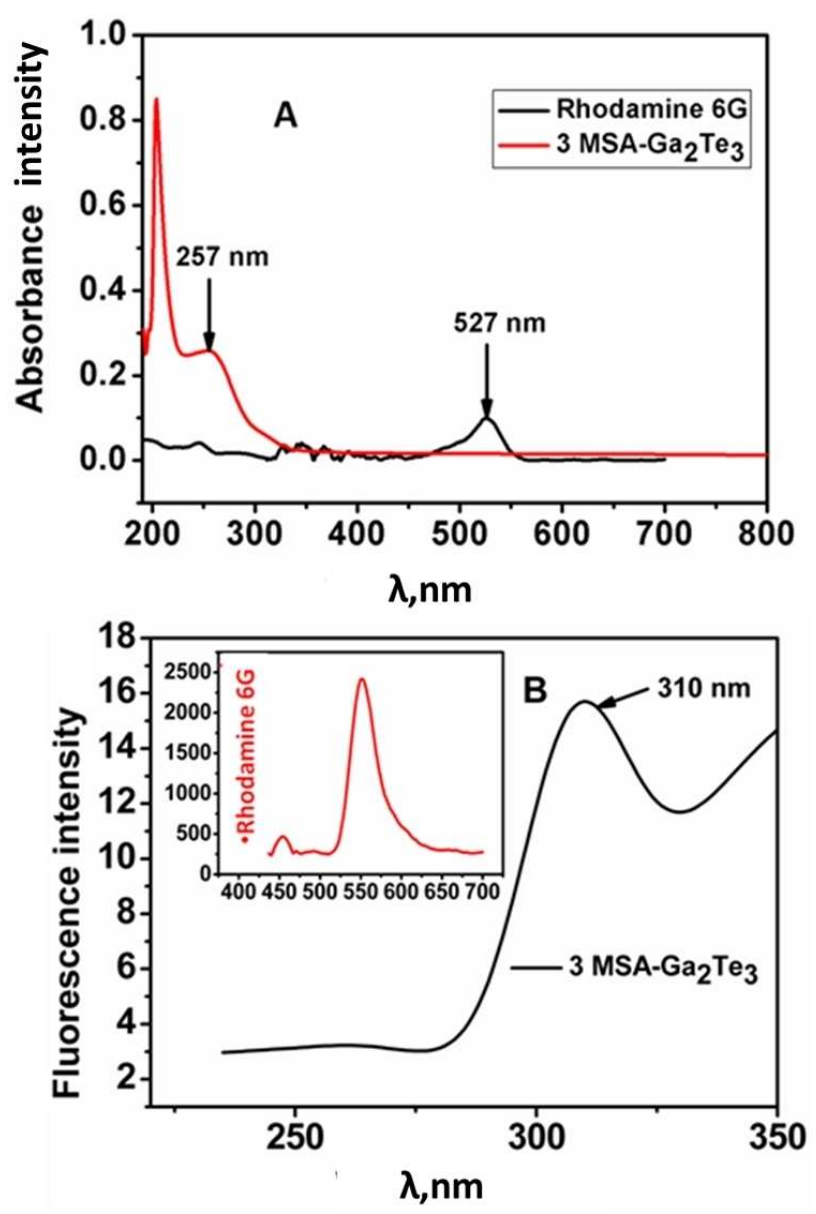

Figure 2. Comparison between rhodamine $6 \mathrm{G}$ and $3 \mathrm{MSA}-\mathrm{Ga}_{2} \mathrm{Te}_{3}$.

rhodamine $6 \mathrm{G}(0.70)$ as expected. The quantum yields were calculated from equations reported in the literature. ${ }^{[2,24]}$ The results suggest that the nanodots have shown to be much more stable than fluorescent dyes as was observed in other results ${ }^{[25,26]}$ in addition to being much brighter. It was estimated by Chan and Nie that 'the fluorescence intensity of a single CdSe QD is equivalent to that of $\sim 20$ rhodamine molecules. ${ }^{[27]}$ This photostability means that quantum dots can be considered as an alternative to fluorescent dyes, notably in biological uses.

\subsection{Structure of $3 \mathrm{MSA}-\mathrm{Ga}_{2} \mathrm{Te}_{3}$}

Modifying the surface of the bimetallic like quantum dots was found to be of great importance in this study. The reason for this was to protect the core shell and avoid the metal ions from leaching out, as this will cause toxicity not only to the environment but also when exposed to the body. Due to these reasons the introduction of the capping agent or ligand to the surface of the quantum dot was investigated. Raman (Figure S2A) was employed to ensure proper surface capping or coating of the quantum dot. While the EDS confirmed the components of the as-synthesized $3 \mathrm{MSA}-\mathrm{Ga}_{2} \mathrm{Te}_{3}$ quantum dot, Figure 3. The elemental composition of the prepared quantum 

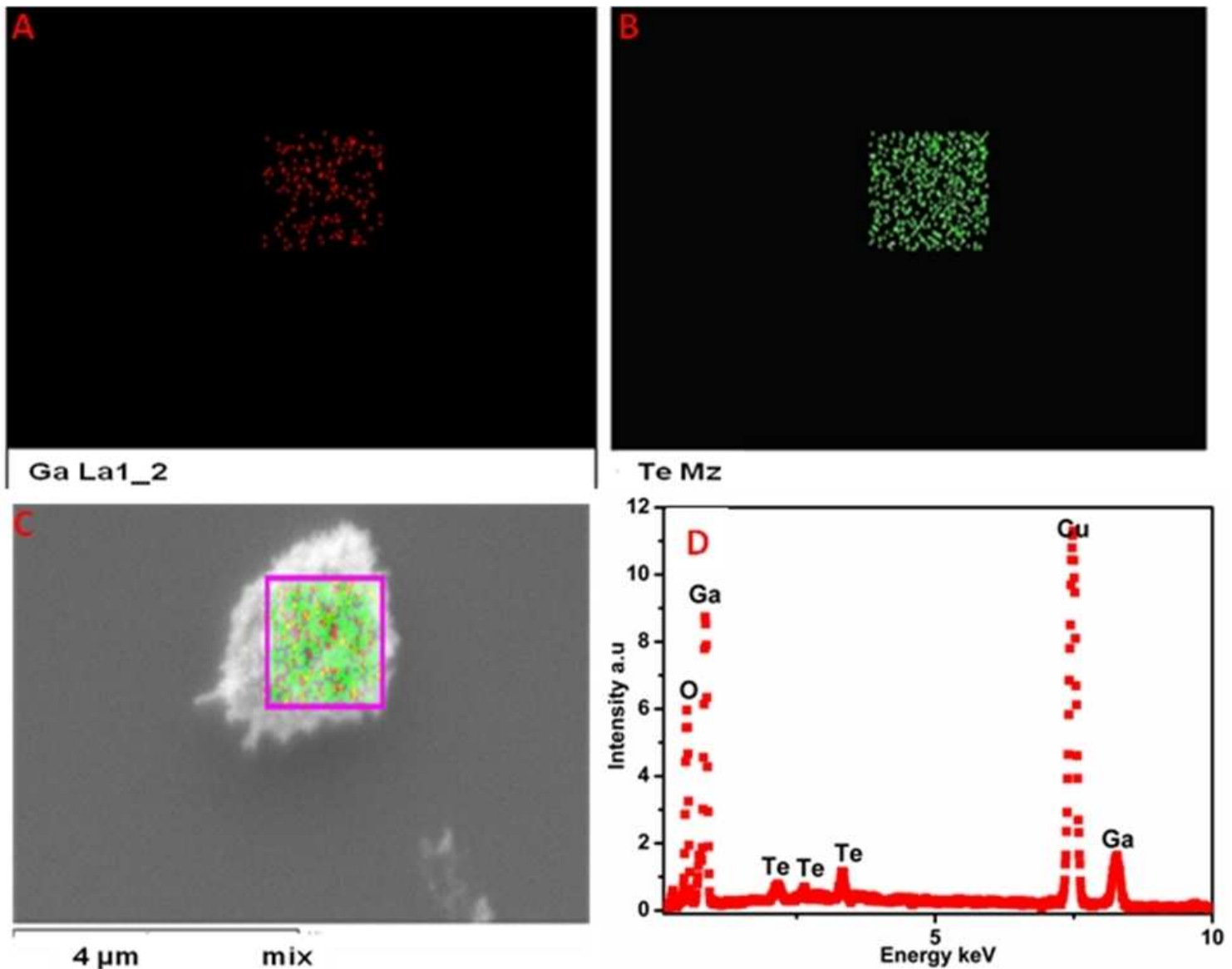

Figure 3. EDS spectrum (D) and the corresponding mapping images (A-C) of $3 \mathrm{MSA}-\mathrm{Ga}_{2} \mathrm{Te}_{3}$

dot was observed from the EDS analysis (Figure 3D), evident by the presence of Te and Ga peaks in the obtained spectra. The elemental peaks were observed across the spectra at different energies ( $1 \mathrm{keV}-9 \mathrm{keV}$ ). Mapping also confirmed the presence of the two elements in the as-synthesized $\mathrm{Ga}_{2} \mathrm{Te}_{3}$ quantum dot (Figure $3 \mathrm{~A}-\mathrm{C}$ ). From both the EDS and mapping, the image intensity/density is almost proportional to the square of the $Z$ number of elements (Ga: $69.72 \mathrm{~g} \mathrm{~mol}^{-1}$ and Te: $127.60 \mathrm{~g} \mathrm{~mol}^{-1}$ ) which also confirms the ratio of the metals been $2: 1$.

In the present work, structural change of powder 3MSA$\mathrm{Ga}_{2} \mathrm{Te}_{3}$ and 3MSA on a glass + tape substrate were investigated by Raman spectroscopy, Figure S2A. The behavioral change of $3 \mathrm{MSA}-\mathrm{Ga}_{2} \mathrm{Te}_{3}$ against 3MSA was scrutinized by observing changes in intensities and shifts in wavenumbers. Raman measurements were made at room temperature in backscatter-

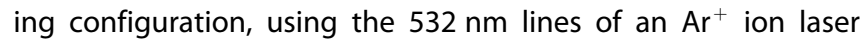
and using a power of the incident laser light.

Raman spectra gave information about the structure and the composition of the samples. Figure S2A shows typical Raman spectra of substrate (tape), 3MSA and $3 \mathrm{MSA}-\mathrm{Ga}_{2} \mathrm{Te}_{3}$ in the range between 50 and $4000 \mathrm{~cm}^{-1}$. As can be seen in Figure S2A, there are no Raman bands observed on a naked substrate. However there are strong 3MSA Raman bands observed at $195 \mathrm{~cm}^{-1}$ (C-C), $385 \mathrm{~cm}^{-1} \delta(\mathrm{SCC}), 1228 \mathrm{~cm}^{-1} \mathrm{tw}$ $(\mathrm{CH} 2), 1628 \mathrm{~cm}^{-1} v(\mathrm{C}=\mathrm{O}), 1946 \mathrm{~cm}^{-1} v(\mathrm{OCO})$. The most intense bands are observed at $308 \mathrm{~cm}^{-1}, 771 \mathrm{~cm}^{-1}, 943 \mathrm{~cm}^{-1}, 670 \mathrm{~cm}^{-1}$, $2562 \mathrm{~cm}^{-1}$ and $2961 \mathrm{~cm}^{-1}$ these bands are characteristic of very weak $\delta(\mathrm{SCC})$, strong $v(\mathrm{SC})_{T}$, weak $\rho(\mathrm{CH} 2), v(\mathrm{CS})_{G}$, very strong $v(\mathrm{SH})$ and $v(\mathrm{CH} 2)$, respectively. The observed bands and/or Raman shifts are in agreement with literature reports, [28; 29] for 3MSA (Figure 5B). Furthermore, these bands confirm the composition of the pure 3MSA structure, Figure 5B. Raman spectra of $3 \mathrm{MSA}-\mathrm{Ga}_{2} \mathrm{Te}_{3}$ (Figure $5 \mathrm{~B}$ ) with chemical structure observed in Figure 5B, was also studied. Literature values for $\mathrm{Ga}_{2} \mathrm{Te}_{3}$ and $\mathrm{Te}$ crystal were found to occur at different wavenumbers. ${ }^{[28,30]}$ There are peaks at 140, 118, and $93 \mathrm{~cm}^{-1}$ which corresponds to the phonon frequencies of $\mathrm{Te}$ and the formation of $\mathrm{Ga}_{2} \mathrm{Te}_{3}$ was assumed to be at $119 \mathrm{~cm}^{-1}$ due to the co-existence of $\mathrm{Te}$ at this location. ${ }^{[30,31]}$ These latter peaks were present in our spectrum, Figure S2B. A strong peak at $93 \mathrm{~cm}^{-1}$ was observed and very weak peaks at $140,118 \mathrm{~cm}^{-1}$ were acquired in our spectrum. Again our obtained data agrees with literature values. ${ }^{[30,31]}$ Compared to $3 \mathrm{MSA}, 3 \mathrm{MSA}-\mathrm{Ga}_{2} \mathrm{Te}_{3}$ showed a vast decrease in the Raman intensities at $308 \mathrm{~cm}^{-1}, 771 \mathrm{~cm}^{-1}$, $943 \mathrm{~cm}^{-1}, 670 \mathrm{~cm}^{-1}, 2562 \mathrm{~cm}^{-1}$ and $2961 \mathrm{~cm}^{-1}$ and red shift from; $670-714 \mathrm{~cm}^{-1}, \quad 771-847 \mathrm{~cm}^{-1}, \quad 943-993 \mathrm{~cm}^{-1}, \quad 1228-$ $1285 \mathrm{~cm}^{-1}$ and $2562-2732 \mathrm{~cm}^{-1}$ was also observed. Based on the data obtained it can be concluded that the quantum dot was properly capped with MSA and the results are comparable with previous results. ${ }^{[32]}$ 
FTIR analyses were carried out to mainly check the presence of 3-mercaptosuccinic acid in the synthesized quantum dots Figure $4 \mathrm{~A}$ and $4 \mathrm{~B}$. Figure $4 \mathrm{~A}$ shows the spectrum of $3 \mathrm{MSA}$ with the vibrational stretches at $3000 \mathrm{~cm}^{-1}, 2500 \mathrm{~cm}^{-1}, 2000 \mathrm{~cm}^{-1}$ and $1500 \mathrm{~cm}^{-1}$ which were associated to $\mathrm{OH},-\mathrm{SH}, \mathrm{C}=\mathrm{O}$ and $\mathrm{C}-\mathrm{H}$ vibrational stretches, respectively. Compared to 3MSA (Figure 4A), the intensity of vibrational stretches in the quantum dots sample decreased with a slight shift in wavenumbers, confirming that the $\mathrm{Ga}_{2} \mathrm{Te}_{3} \mathrm{QD}$ are well capped with 3MSA.

\subsection{Morphology and Crystallinity of $3 \mathrm{MSA}-\mathrm{Ga}_{2} \mathrm{Te}_{3}$}

As reviewed from literature, size of quantum dot can be of vital importance as far as toxicity is concerned. Arguably the smaller the size of the nanodots the higher the toxicity since there's more penetration of the quantum dot and versa vice. This theory was put into test in our cytotoxicity study. Before carrying-out the toxicity study the novel water-soluble 3MSA$\mathrm{Ga}_{2} \mathrm{Te}_{3}$ quantum dot was characterized using several microscopic and spectroscopic techniques such as HRTEM, STEM, AFM, and XRD. This was done to determining the particle size, chemical composition and/or formation of the as-prepared 3 $\mathrm{MSA}-\mathrm{Ga}_{2} \mathrm{Te}_{3}$ quantum dot. Silicon wafer was used as the sample holder for the distribution of the $3 \mathrm{MSA}-\mathrm{Ga}_{2} \mathrm{Te}_{3}$ nanomaterials. As both FTIR and EDS, XPS is also used as one of the techniques for analyzing the surface chemistry of a material. The technique is used to measure the elemental composition, empirical formula, chemical state and electronic state of the elements within a material. The components and structure of the assynthesized $3 \mathrm{MSA}-\mathrm{Ga}_{2} \mathrm{Te}_{3}$ quantum dots are as shown in Figure 5.

Chemical states of the elements C, O, Ga and Te can be identified from the high resolution spectra during XPS analysis, Figure 5A, C and D. Figure 5A shows a wide XPS spectrum, and the positions of the main typical peaks of $\mathrm{Ga}_{2} \mathrm{Te}_{3}$ on silicon substrate. Ga:Te surface concentration was found to be 1:5.6

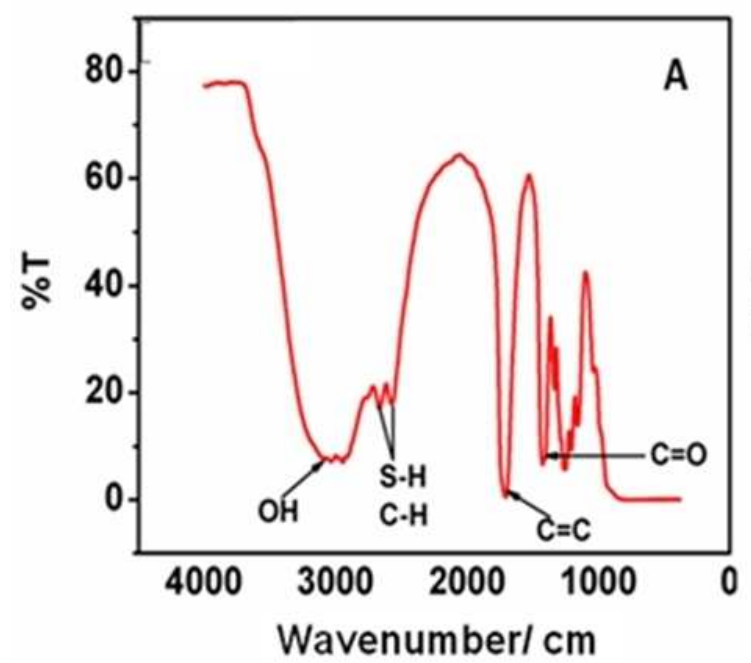

which is higher than the expected Ga:Te composition. This indicates that the surface is Te enriched and possibly $\mathrm{Ga}$ and $\mathrm{Te}$ may be present in more than one oxidation state. Photoemission measurements on the $\mathrm{Ga} 2 \mathrm{p}$, Te $3 \mathrm{~d}$ and $\mathrm{O} 1 \mathrm{~s}$ core lines were used to evaluate the structural chemistry of the chemically treated surfaces. The surface has a Ga 2 p3/2 peak binding energy of $1118 \mathrm{eV}$ which can be interpreted as GaTe, Figure 5C. Figure $5 \mathrm{D}$ reveals the $\mathrm{Te} 3 \mathrm{~d}$ spectrum of as-prepared GaTe surface and shows two pairs of $\mathrm{Te} 3 \mathrm{~d} 5 / 2,3 / 2$ states $^{[33,34]}$ at $578 \mathrm{eV}$ and $588 \mathrm{eV}$, respectively. The lower binding energy peak at $578 \mathrm{eV}$ represents the lattice bound $\mathrm{Te}$ in GaTe while the higher binding energy represents $\mathrm{Te}^{4+}$ in the bulk. ${ }^{[33,34]}$ Additionally, the $\mathrm{O} 1 \mathrm{~s}$ peak shows a binding energy peak at $580 \mathrm{eV}$ (Figure 5A) which can be attributed to the bulk precursors $\mathrm{Ga}_{2} \mathrm{O}_{3}$ and $\mathrm{Te}$, [33;34] respectively. XPS and XRD analysis illustrates clear evidence of oxidation of the surfaces material which corroborates well with other techniques such as Raman fingerprints and $\mathrm{CV}$ in the mechanism of formation. As reviewed in literature ${ }^{[35,36]}$ the XRD patterns (Figure $5 B$ ) of the nanodots are indexed/associated to the cubic phase (zinc blende/ sphalerites) structures with lattice constant, $a=5.8913 \mathrm{~nm}$. It is known that the zinc blende structures have tetrahedral coordinates and forms a face-centered cubic (fcc) lattices (Each atom is surrounded/consist of four atoms of the differing type) which confirms the behavior of $3 \mathrm{MSA}-\mathrm{Ga}_{2} \mathrm{Te}_{3}$.

$3 \mathrm{MSA}-\mathrm{Ga}_{2} \mathrm{Te}_{3}$ quantum dot with the average particle size of $20 \pm 2 \mathrm{~nm}$ were evenly distributed on the silicon substrate as shown by the HRTEM and STEM images, Figure $5 E$ and $G$ ) while Figure 5F-insert reveals the $d$-spacing of the prepared $\mathrm{QD}$. The lattice fringe of individual quantum dot with the lattice space $(d$ space) of $0.2 \mathrm{~nm}$ (Figure 5F: insert) were found to be in the same direction thus confirming the single-single crystallinity of the nanomaterials and conform to be that of zinc-blende. STEM image conforms to the results observed in HRTEM, apparent by the structural morphology and the average particle size of $5 \pm$ $20 \mathrm{~nm}$ which is well within range required for the dimensionless quantum dot (Figure 5G). AFM was also employed in determin-

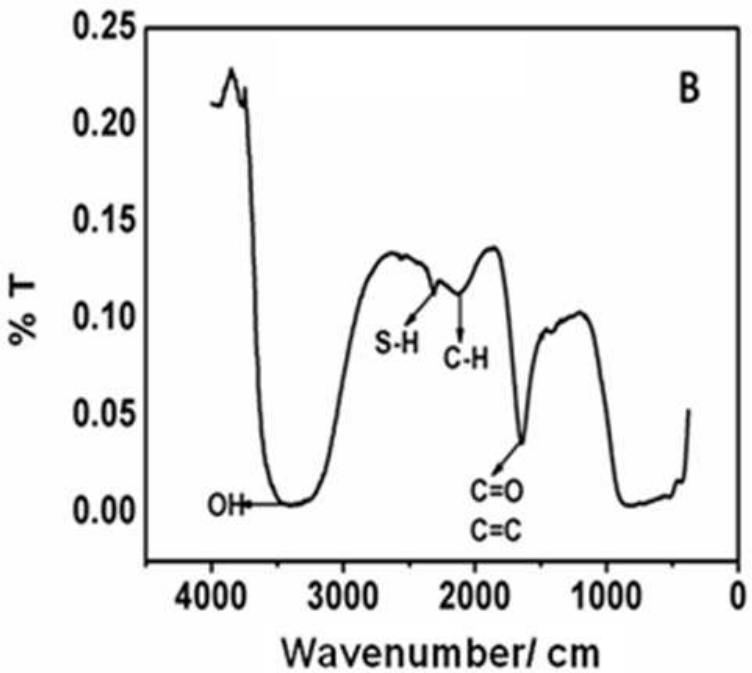

Figure 4. FTIR spectra for A) $3 M S A$ and $B) \mathrm{Ga}_{2} \mathrm{Te}_{3}-3 \mathrm{MSA}$. 

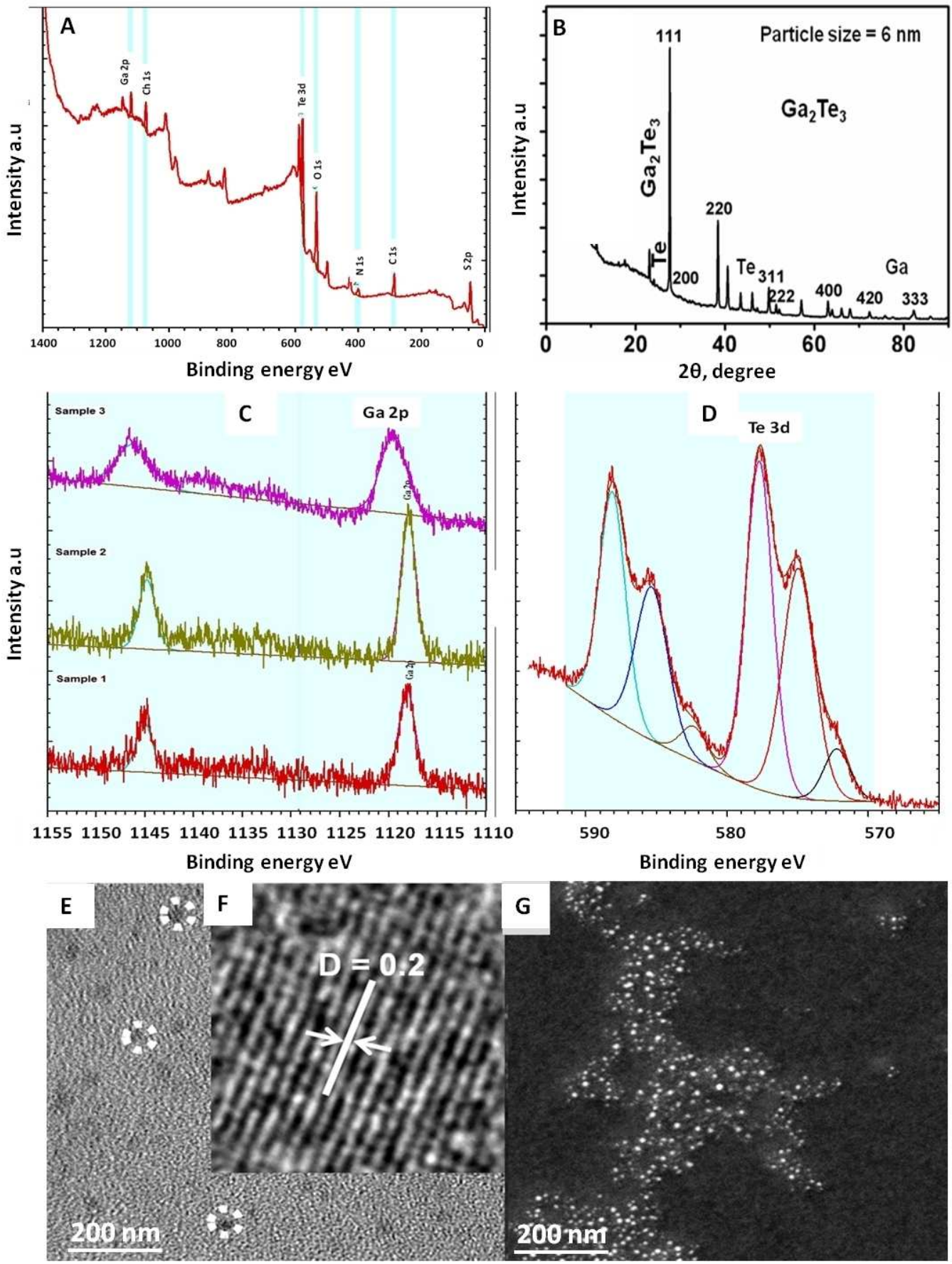

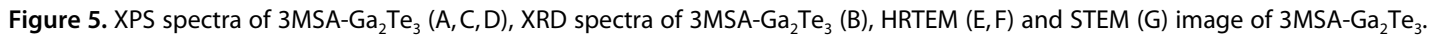

ing the particle size of the $3 \mathrm{MSA}-\mathrm{Ga}_{2} \mathrm{Te}_{3}$ quantum dot. As in other analysis silicon wafer was also used as the sample holder for the immobilization of the QD. The sample was analyzed in air using a non-contact or a tapping mode due to sample softness. AFM image of the synthesized 3MSA-Ga $\mathrm{Te}_{3}$ QD are as shown in Figure S3A, B, C and D. Images of bare silicon substrate in Figure S3A showed no particle distribution, confirming that the substrate was not immobilized with the quantum dot ( $3 \mathrm{MSA}-\mathrm{Ga}_{2} \mathrm{Te}_{3}$ ). Compared to bare silicon substrate, the topography image of the quantum dot was found to have a large number of as-prepared quantum dots distributed on the surface of the silicon substrate. However, the QD was found to be slightly agglomerated; this can be due to improper heating and sonication. Nonetheless, there were more particles with the average diameter of $20 \mathrm{~nm}$ observed. The modified silicon wafer was found to have higher surface roughness (36.9) compared to the unmodified silicon wafer (0.03), Figure S3A and $\mathrm{B}$. A clear distinction of the nanomaterials was observed from the $3 D$ images, Figure S3C. The structural morphology of the quantum dots was found to be more globular and oval as is 
expected to be the nature of the QD. The results obtained were comparable with that of HRTEM, STEM images and also with other synthesized quantum dot (e.g. CdTe, CdSe etc.) from literature if morphology and size is concerned. ${ }^{[1]}$ The distribution of the quantum dot was also confirmed by the histogram image obtained, Figure S3D. The particle distribution ranged from $19.2-76 \mathrm{~nm}$, covering $80 \%$ of the substrate surface.

\subsection{Hydrophilicity of the $3 \mathrm{MSA}-\mathrm{Ga}_{2} \mathrm{Te}_{3}$ Quantum Dots}

Contact angle is a principal control of the flow of multiple fluid phases through porous media. Mercaptosuccinic acid (3MSA) is known to be an amphiphilic molecule, which assist other molecules or compounds to become more water-soluble. In this study contact angle measurements were carried out to investigate or confirm the effect of 3MSA on capped quantum dot $\left(3 \mathrm{MSA}-\mathrm{Ga}_{2} \mathrm{Te}_{3}\right)$. Additionally, the hydrophilic and hydrophobic nature of the two samples ( $3 \mathrm{MSA}-\mathrm{Ga}_{2} \mathrm{Te}_{3}$ and $\mathrm{Ga}_{2} \mathrm{Te}_{3}$ ) was investigated by employing drop sensor analyzer whereby a contact angle measurement of each was determined.

We have conducted several measurements, and investigated two different powdered phase samples on a solid surface; water being the only aqueous phase: Figure 6 (A) Deionized water, (B) $\mathrm{Ga}_{2} \mathrm{Te}_{3}$ and (C) $3 \mathrm{MSA}-\mathrm{Ga}_{2} \mathrm{Te}_{3}$. Compared to the naked quantum dots $\left(\mathrm{Ga}_{2} \mathrm{Te}_{3}\right)$, it can be concluded that the capped quantum dot (3MSA- $\mathrm{Ga}_{2} \mathrm{Te}_{3}$ ) are strongly water-wet and confirm that the 3MSA had an effect on the wettability or the partly solubility of the capped $\mathrm{Ga}_{2} \mathrm{Te}_{3}$ quantum dot. The obtained results put a clear picture in understanding the hydrophilic nature of the quantum dot and also give us an opportunity to investigate other capping agent which can aid in the solubility of the QD for biological applications.

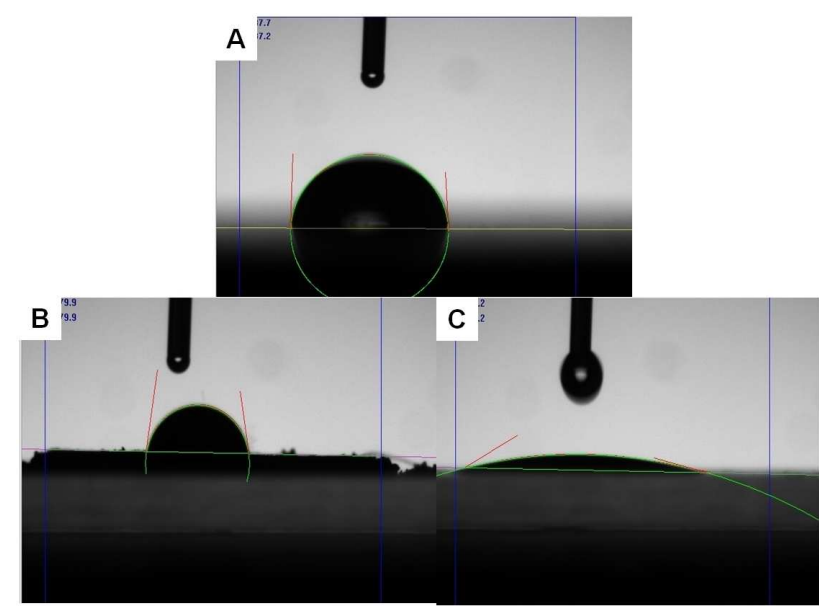

Figure 6. Hydrophobic surface and hydrophilic surface of $A$ ) solid surface (blank), B) $\mathrm{Ga}_{2} \mathrm{Te}_{3}$, and C) 3MSA-Ga $\mathrm{Te}_{3}$.

\section{Mechanism and Genosensor Studies}

The reaction mechanism for fabricated GC electrode is as shown in Scheme $1 A$ and B. The electrode was chosen due to its compatibility with MSA capped quantum dot. We functionalized core $\mathrm{Ga}_{2} \mathrm{Te}_{3}$ quantum dot with short-chain 3-mercaptosuccinic acid to render these semiconductors water-soluble. Through the formation of an amide linkage, the surface provided coupling sites for amine modified DNA attachment. In detail; the first step is the protonation of the carbodiimide, EDC, giving a carbocation 1, which is hydrolyzed into a urea derivate 1 in the absence of a dissociated carboxylic acid. In the presence of carboxylate, carbocation $\mathbf{2}$ is attacked giving $\mathbf{O}$-acylisourea $\mathbf{3}$. Up until this step the stoichiometric of $\mathrm{H}^{+}$shows that one proton is consumed for each $\mathrm{O}$-acylisourea $\mathbf{3}$ formed. From here on different scenarios are possible depending on the reaction conditions. Since the EDC forms an unstable amide bond formation due to the regeneration of the carboxylic group and hydrolysis will occur (more water formation) rather than the formation of primary amine, thus a product called $\mathrm{N}$-acylurea is formed. For the reasons, $\mathrm{N}$-hydroxysuccinimide (NHS) is employed since it is more advantageous than the later (EDC). NHS is a less hydrolysis-sensitive compound, and is more reactive towards primary amines. When NHS reacts with $\mathrm{O}$-acylisourea, a succinimidyl ester is formed, which is more stable towards hydrolysis $\left(\mathrm{t}_{1 / 2} \text { of } 40 \mathrm{~min} \text { at } \mathrm{pH} \mathrm{6.0)}\right)^{[37]}$ Scheme 1B. In addition, the formation of $\mathrm{N}$-acylurea is hindered since the succinimidyl ester cannot undergo $\mathrm{N} \rightarrow \mathrm{O}$ displacement as is the case for EDC. The mechanism is as follows; the dissociated hydroxyl group of NHS 4 makes a nucleophilic attack on $\mathrm{O}$-acylisourea 3, giving urea derivative and succinimidyl ester 5 , which can then be attacked by a non-dissociated primary amine, resulting in the amide 6 and regenerating NHS 5. The conversion of $O-$ acylisourea to a succinimidyl ester has enabled the formation of amide. ${ }^{[37-39]}$

The electrochemical behavior and response of bare $\mathrm{GCE}$, GCE/3MSA- $\mathrm{Ga}_{2} \mathrm{Te}_{3} / \mathrm{dsDNA}$ and GCE/3MSA- $\mathrm{Ga}_{2} \mathrm{Te}_{3}$ were investigated prior to DNA sensing/hybridization. From Figure $7 \mathrm{~B}$, both bare GCE and 3MSA-GCE showed no redox properties which are a typical behavior of bare GCE in phosphate buffered solution. However, an increase in current was observed when the bare electrode was immersed in 3MSA solution revealing that the capping agent may also have a co-catalytic effect. In addition, the $\mathrm{GCE} / 3 \mathrm{MSA}-\mathrm{Ga}_{2} \mathrm{Te}_{3}$ revealed a prominent oxidation peaks at $E_{p}=400 \mathrm{mV}$ which shifted to $E_{p}=500 \mathrm{mV}$ upon introduction of ssDNA, Figure 7B. Moreover, a decrease in peak current was also observed confirming the interaction of the quantum dot and the ssDNA. Thus, since the ssDNA (Figure 7A) showed two distinctive oxidation peaks (associated with guanine) at $E_{p}=$ $450 \mathrm{mV}$ as well as at $E_{p}=850 \mathrm{mV}$, it was clear that a peak at $E_{p}=$ $450 \mathrm{mV}$ will be used to monitor the interaction of the probemodified electrode with the target DNA (Figure 7C), this decision was taken due to a clear shift and a catalytic effect observed.

The genosensor response showed the binding-event that occurred upon introduction of $0.5 \mathrm{nM}$ of Her2 oncogene, Figure $7 C$. The voltammogram revealed a decrease in peak 

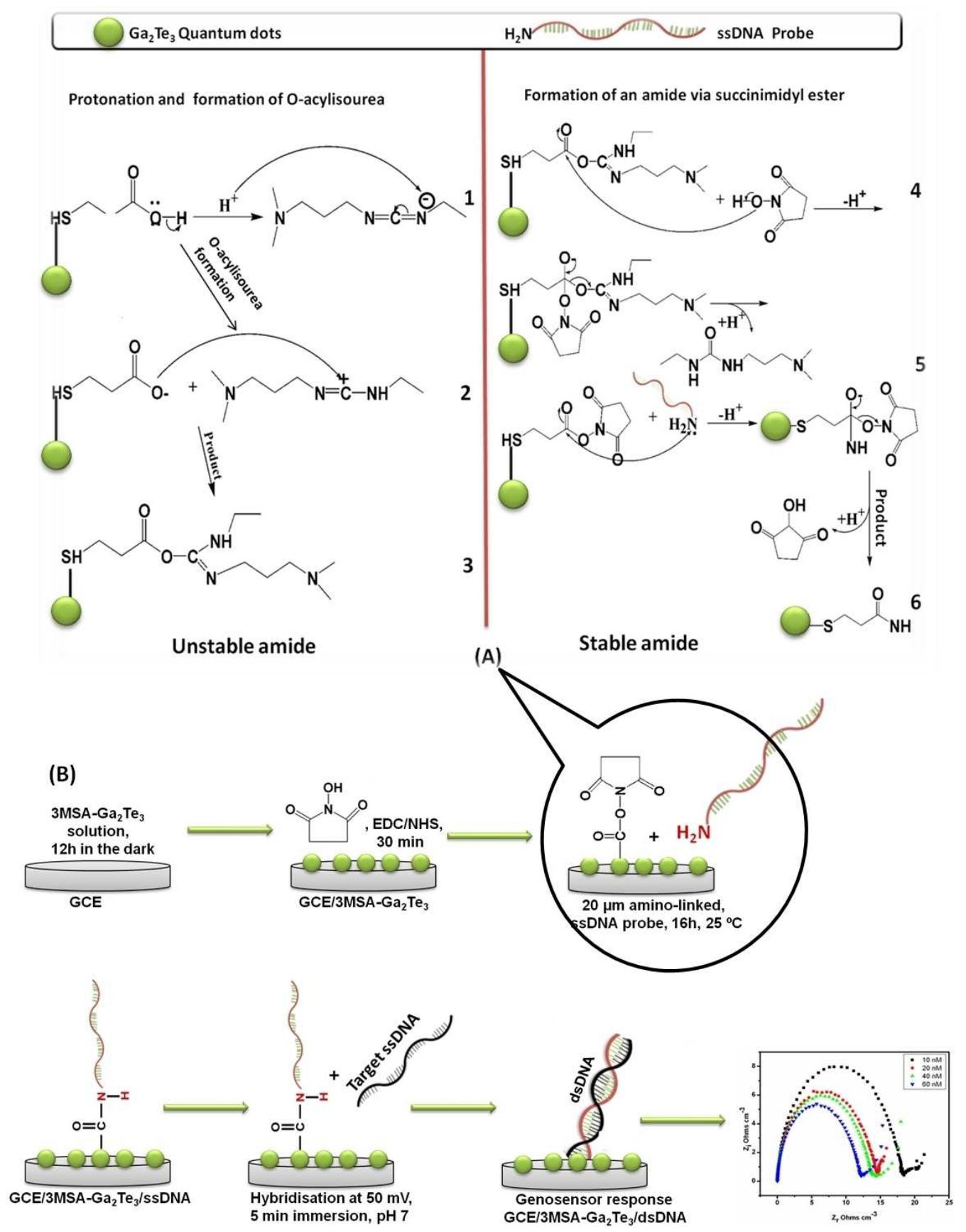

Scheme 1. A) Reaction mechanism of $3 \mathrm{MSA}-\mathrm{Ga}_{2} \mathrm{Te}_{3}$ with linkers (EDC/NHS). B) Molecular structure of GCE/3MSA-Ga $\mathrm{Te}_{3} / \mathrm{DNA}-\mathrm{DNA}$ assembly/interaction.

current as we increase the concentration, confirming the interaction and binding of the analyte and the probe-ssDNA at the electrode interface. A change in peak potential (from $500 \mathrm{mV}$ to $400 \mathrm{mV}$ ) was observed, which is typical of slow electron movement at the electrode interface. Figure 7D represents the corresponding genosensor calibration plot which reached its saturation maxima at $4 \mathrm{nM}$. The genosensor sensitivity was calculated to be $3.1 \times 10^{-2} \mu \mathrm{Ang}-1 \mathrm{~mL}^{-1}$, the linear dynamic range (LDR) was calculated to be $0.1-$ $2.0 \mathrm{ng} \mathrm{mL}^{-1}$ and by using eq. ${ }^{2}$ below on the criterion of a signalto-noise ratio of 3 its limit of detection (LOD) was found to be
$0.45 \mathrm{pg} \mathrm{mL}^{-1}$. The obtained genosensor's results are comparable to those reported in the literature ${ }^{[28,38,39,40,41]}$ and show very low detection limit compared to existing DNA assays [Eq. (2)]. ${ }^{[39-41]}$

$$
L O D=\frac{3 S D}{\text { Slope }}
$$

In this paper, we further investigate the mechanism of DNAQD interaction before and after hybridization, Figure 8-10. An important property of quantum dot is that they can easily transfer energy when excited and this form of energy is 

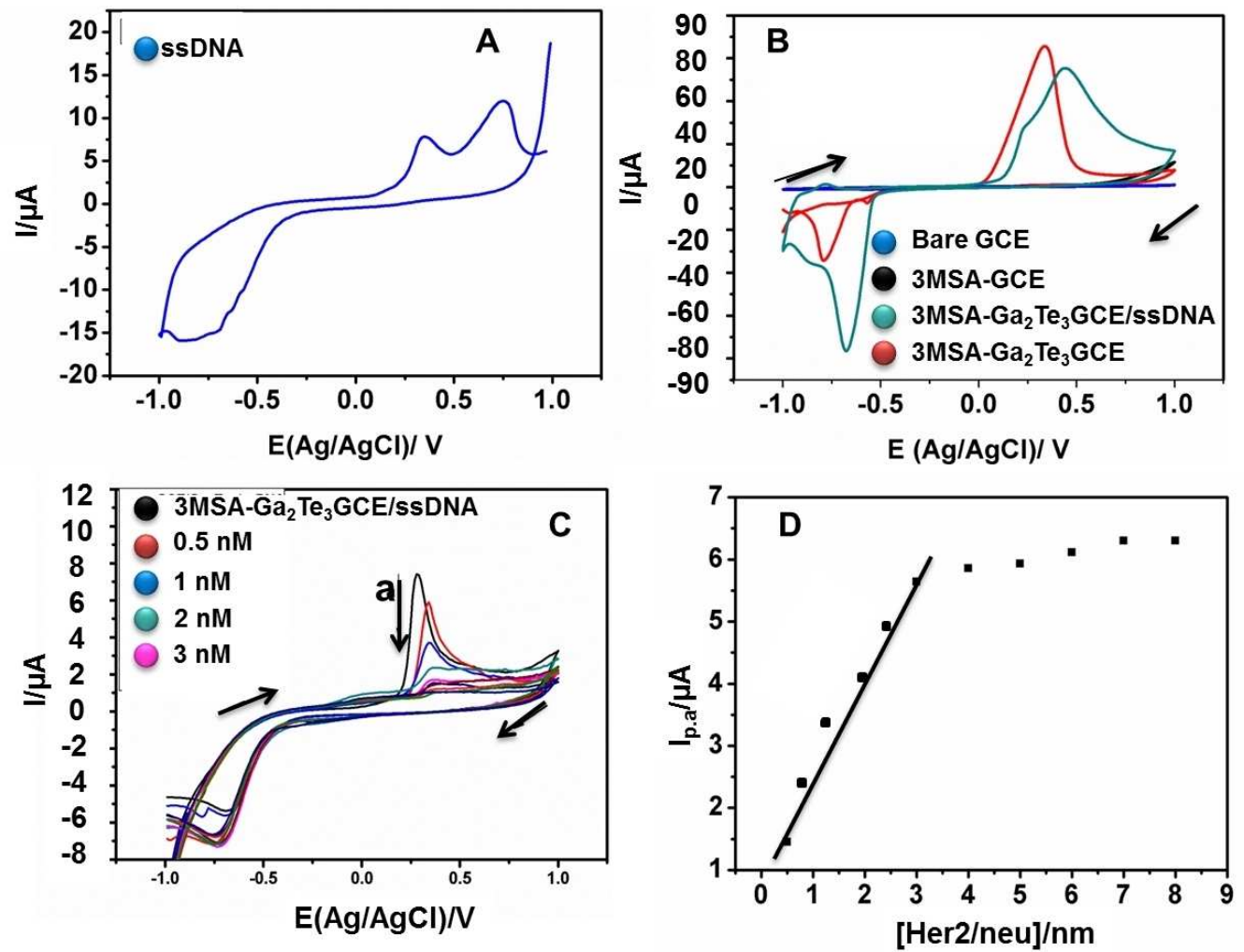

Figure 7. Cyclic voltammetric responses of electrode systems of $A$ ) ssDNA and B) bare GCE, 3MSA-GCE, GCE/3MSA-Ga $\mathrm{Te}_{3}$ and GCE/3MSA-Ga $\mathrm{Te}_{3} / \mathrm{ssDNA}$. Experiments were performed in $0.1 \mathrm{M} \mathrm{PBS}(\mathrm{pH}=7.4)$ at $25 \mathrm{mV} \mathrm{s}^{-1}$. Genosensor (GCE/3MSA-Ga $\left.\mathrm{Te}_{3} / \mathrm{ssDNA}\right)$ responses to Her2 oncogene: C) CVs, D) calibration curve from CV data.

calculated as $\mathrm{E}_{\mathrm{g}}$ in Figure 1. In our case the nanodot transferred energy in the form of a signal (current, A) when the voltage was passed on the quantum dots and this was also shown in Figure 1 and 2 by the resultant photostability value and band gap energies. Since quantum dots are semiconductors (as proven in Figure 1) they passed this energy on to a nearby molecule which is through the capping ligand attached to the quantum dots to the ssDNA-capture probe, which eventual gave a current signal due to the quantum energy. Consequently, different experimental analyses have been carried out in order to pin-point the role of $3 \mathrm{MSA}-\mathrm{Ga}_{2} \mathrm{Te}_{3}$ with DNA and how the cations/anions affect the detection-signal (DNA-QD).

Since the oxidation potential was shown to be dependent to the reduction potential of the quantum dot, a potential dependence study was carried out to prove that the latter is true. Figure 10 shows the behavior of the peak current and peak potential of the $3 \mathrm{MSA}-\mathrm{Ga}_{2} \mathrm{Te}_{3}$ quantum dot at the same scan rate but different potential windows. An oxidation peak current $\left(l_{p, a}\right)$ was evident at $E_{p}=0.43 \mathrm{~V}$ vs. $\mathrm{Ag} / \mathrm{AgCl}$ (Figure $8 \mathrm{~A}, \mathrm{~b}$ ) and a reduction peak current at $\left(I_{p, c}\right)$ was observed at $E_{p}=$ $-0.65 \mathrm{~V}$ vs. $\mathrm{Ag} / \mathrm{AgCl}$, Figure $8 \mathrm{~A}, \mathrm{~b}$. These two redox peaks which were due to the interaction of the probe DNA and $3 \mathrm{MSA}-\mathrm{Ga}_{2} \mathrm{Te}_{3}$ were used to monitor the potential dependence of the genosensor.

From Figure $8 \mathrm{~A}$, it is evident that as we move from higher potentials to lower potentials $(-1.0 \mathrm{~V}$ to $0 \mathrm{~V}$ and $1.0 \mathrm{~V}$ to $0 \mathrm{~V})$ the peak current at $0.4 \mathrm{~V}$ decreases in intensity. Concurrently, a shift in peak potential was also observed as we move towards lower potentials, confirming an irreversible system. A calibration plot of potential vs. current was used to clearly show this behavior, Figure $8 \mathrm{~B}$. It is clear from this figure that at higher potentials $(-1.0$ to $-0.5 \mathrm{~V})$, higher peak currents are observed and at lower potentials of $-0.4 \mathrm{~V}$ to $-0.1 \mathrm{~V}$ the peak currents decrease and are almost constant. Additionally, the behavior in peak potentials and peak currents proves that both the oxidation and the reduction peaks are dependent to each other. Hence a wider potential window was chosen. From the observed data more experiments had to be carried out in order to account for the peculiar behavior in peak potentials. At first glance the behavior in peak potentials was associated with the anions and cations that interacted with the unreacted Te from the quantum dot $\left(3 \mathrm{MSA}-\mathrm{Ga}_{2} \mathrm{Te}_{3}\right)$ surface. From the bimetallic point of view, it's common knowledge that when two metals interact to form a compound or a quantum dot in our case, one of the metals tends to move towards the surface of the overall bulk material (some unreacted metals). It is this unreacted nanomaterial on the surface of the quantum dot which is been investigated. The aim here is to determine the effect of quantum dot (3MSA- $\mathrm{Ga}_{2} \mathrm{Te}_{3}$ ) which is Te enriched, interacting with the ssDNA whilst studying the overall reaction of genosensor ( $3 \mathrm{MSA}-\mathrm{Ga}_{2} \mathrm{Te}_{3} / \mathrm{ssDNA}$ ) with the ions. Figure 9, shows the behavior of different cations with the genosensor (3MSA$\mathrm{Ga}_{2} \mathrm{Te}_{3} / \mathrm{ssDNA}$ ) before hybridization. From Figure $9 \mathrm{~A}$, both lithium ions and cesium ions were two species that clearly 

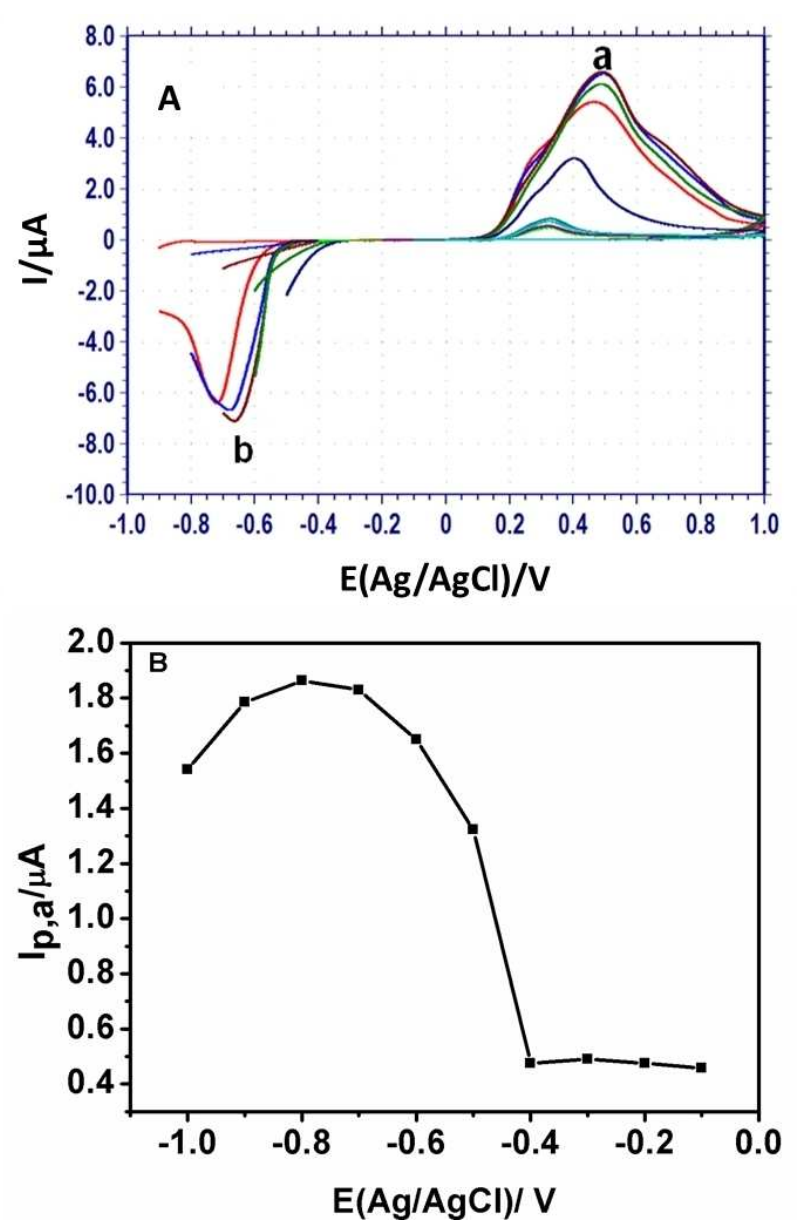

Figure 8. $\mathrm{CV}$ data for A) GCE/3MSA-Ga $\mathrm{Te}_{3} / \mathrm{ssDNA}$ at different potential windows $(-0.1 \mathrm{~V}-1.0 \mathrm{~V},-0.2 \mathrm{~V}-1.0 \mathrm{~V},-0.3 \mathrm{~V}-1.0 \mathrm{~V},-0.4 \mathrm{~V}-1.0 \mathrm{~V},-0.5 \mathrm{~V}-$ $1.0 \mathrm{~V},-0.6 \mathrm{~V}-1.0 \mathrm{~V},-0.7 \mathrm{~V}-1.0 \mathrm{~V}-0.7 \mathrm{~V}-1.0 \mathrm{~V}$ ) at $25 \mathrm{mVs}^{-1}$ in $0.1 \mathrm{M} \mathrm{PBs}$, $\mathrm{pH} 7$ and $\mathrm{B}$ ) corresponding calibration curve in (A). showed a good interaction with the genosensor. The ionic radii of $\mathrm{Cs}^{+}$was higher $1.65 \AA$ (Figure $9 \mathrm{~B}$ ) compared to other cations showing that there's more steric hindrance. However, $\mathrm{Li}^{+}$with the smallest sensitivity and smallest peak current was also noted to have the smallest ionic radii $0.45 \AA$ (Figure 9B) thus showing less steric hindrance.

The obtained data suggests that as we go down the period there's higher electronegativity and the opposite is true. Based on these observations further analysis was carried out to investigate the behavior of the two cations with the genosensor (GCE/3MSA- $\mathrm{Ga}_{2} \mathrm{Te}_{3} / \mathrm{ssDNA}$ ) before and during hybridization. For convenience only the cation results will be show $\left(\mathrm{Li}^{+}\right)$. Figure $9 \mathrm{~A}$, shows the genosensor interaction with different concentrations $(0.10-8.00 \mathrm{nM})$ of target analyte while introducing more cations on the electrode surface. Before introducing the analytes or the electrolyte into the system the following redox peaks were observed; Cyclic voltammograms with redox properties of GCE/3MSA-Ga $\mathrm{Te}_{3}$-ssDNA were observed with an oxidation peak potential $\left(I_{p, a}\right)$ at $E_{p}=600 \mathrm{mV}$ and a reduction peak potential $\left(I_{p, c}\right)$ at $E_{p}=-500 \mathrm{mV}$ which was associated with redox properties of $\mathrm{Ga}^{3+}$. An additional reduction peak was observed at reduction peak potential $\left(I_{p, a}\right)$ of $E_{p}=-700 \mathrm{mV}$ which can be due to the products of the $\mathrm{Te}^{2-} \cdot{ }^{28]}$

The introduction of cations was done by washing the immobilized electrode with $0.1 \mathrm{M}$ of $\mathrm{Cs}^{+} / \mathrm{Li}^{+}$solutions after each binding or hybridization with target analyte and also using the aliquots as the electrolytes. Compare to the phosphate buffer $\left(\mathrm{K}^{+}\right)$system, the $\mathrm{Cs}^{+}$system (not shown) and $\mathrm{Li}^{+}$system showed higher sensitivity $\left(2.74-3.69 \mathrm{ng} \mathrm{mL}^{-1} \mathrm{~A}^{-1}: r^{2}=0.99\right)$ and very low detection limits $\left(0.4 \mathrm{pg} \mathrm{mL}^{-1}\right)$ with the linear dynamic range starting from $0.1-1 \mathrm{ng} \mathrm{mL}^{-1}$ ), Figure $10 \mathrm{~A}$ and $\mathrm{B}$. The genosensor cation interaction showed a decrease in peak current after the first addition of the target analyte and reached its point of saturation after adding $1 \mathrm{nM}$ of Her2/neu concentration. The observed behavior suggest an interaction between the tellurium enriched $3 \mathrm{MSA}-\mathrm{Ga}_{2} \mathrm{Te}_{3}$ with cations, whilst binding
A

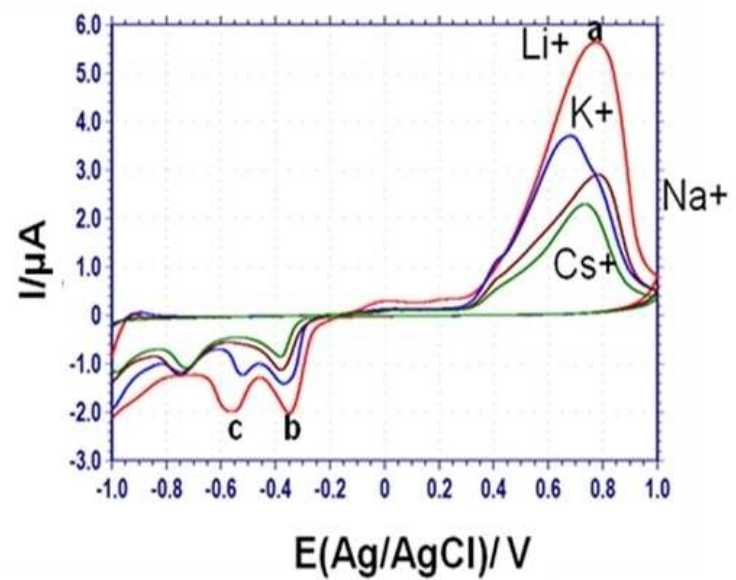

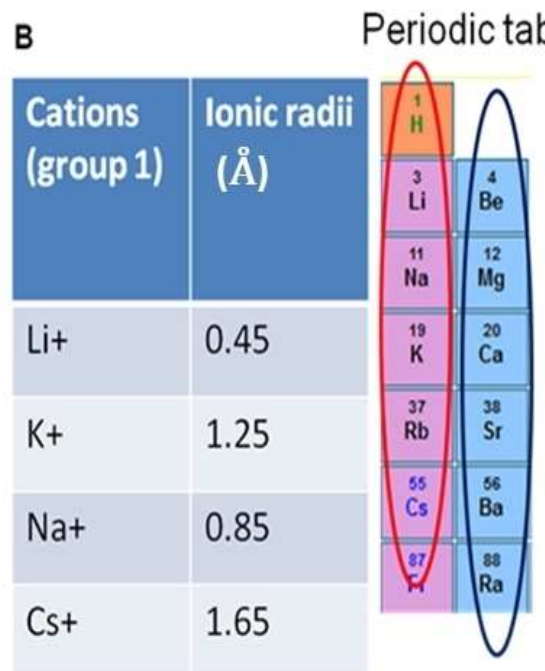

Figure 9. Genosensor response. A) CV of GCE/3MSA-Ga $\mathrm{Te}_{3} / \mathrm{ssDNA}$ with different cations but same concentrations (0.1 M). B) Table showing the electronegativity of different cations together with a periodic table with elements from group 1 and 2. 

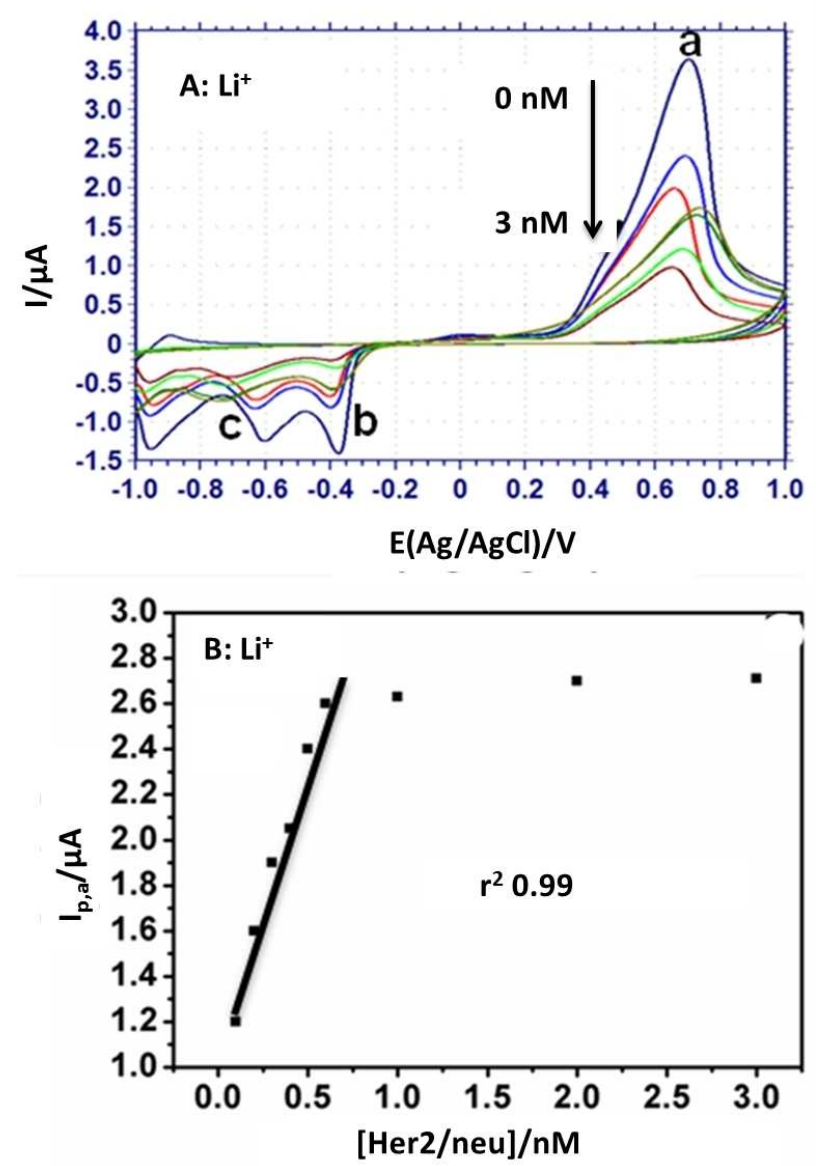

Figure 10. CVs. A) Effect of electrolyte on genosensor response. B) Calibration curve of Her2/oncogene with data from (A). CVs Experiments were performed in $0.1 \mathrm{M} \mathrm{LiCl}$ at $25 \mathrm{mV} \mathrm{s}^{-1}$.

to the target analyte, which formed $3 \mathrm{MSA}-\mathrm{Ga}_{2} \mathrm{Te}_{3} / \mathrm{dsDNA} / \mathrm{Cs}^{+}$/ $\mathrm{Li}^{+}$.

Based on our findings or obtained data a mechanism for the genosensor was proposed, Scheme $2 \mathrm{~A}$ and B. From our findings it was observed that there was an interaction between the cations and the tellurium nanoparticles on the surface of the quantum dots that caused a shift and a decrease in signal at $500 \mathrm{mV}$, as we increase the concentration of the $\mathrm{Li}^{+}$. What we are proposing here is that the electrons from the bulk electrode are pumped to the adsorbed species ( $3 \mathrm{MSA}-\mathrm{Ga}_{2} \mathrm{Te}_{3}$ ) into the electrolyte solution and back to the electrode or in between the quantum dot (Scheme $2 \mathrm{~A}$ and $\mathrm{B}$ ) giving energy to semiconductor hence a higher signal response. The free electrons from the electrolyte solution $\left(\mathrm{Li}^{+}\right)$interact with the adsorbed species of tellurium that acts as shell of the core quantum dots. This behavior was also observed from XPS and XRD data (Figure 5) where $\mathrm{Te}^{4+10}$ moved to the surface of 3MSA QD, thus forming a shell indicating that the surface is Te enriched (evidence by high surface ratio $1: 5.6$ and more than one oxidation state). The electrons from $\mathrm{Li}^{+}$forces the $\mathrm{Te}^{0}$ to be reduced back to $\mathrm{Te}^{2-}$ (rxn: $\mathrm{Te}^{0}+2 \mathrm{e}^{-} \rightarrow \mathrm{Te}^{2-}$ ) thus forming an adsorbed complex: $\mathrm{Te}^{2-}+\mathrm{Li}^{+} \rightarrow \mathrm{Te}-2 \mathrm{Li}$. This adsorption complex is believed to be behind the genosensor response in which a

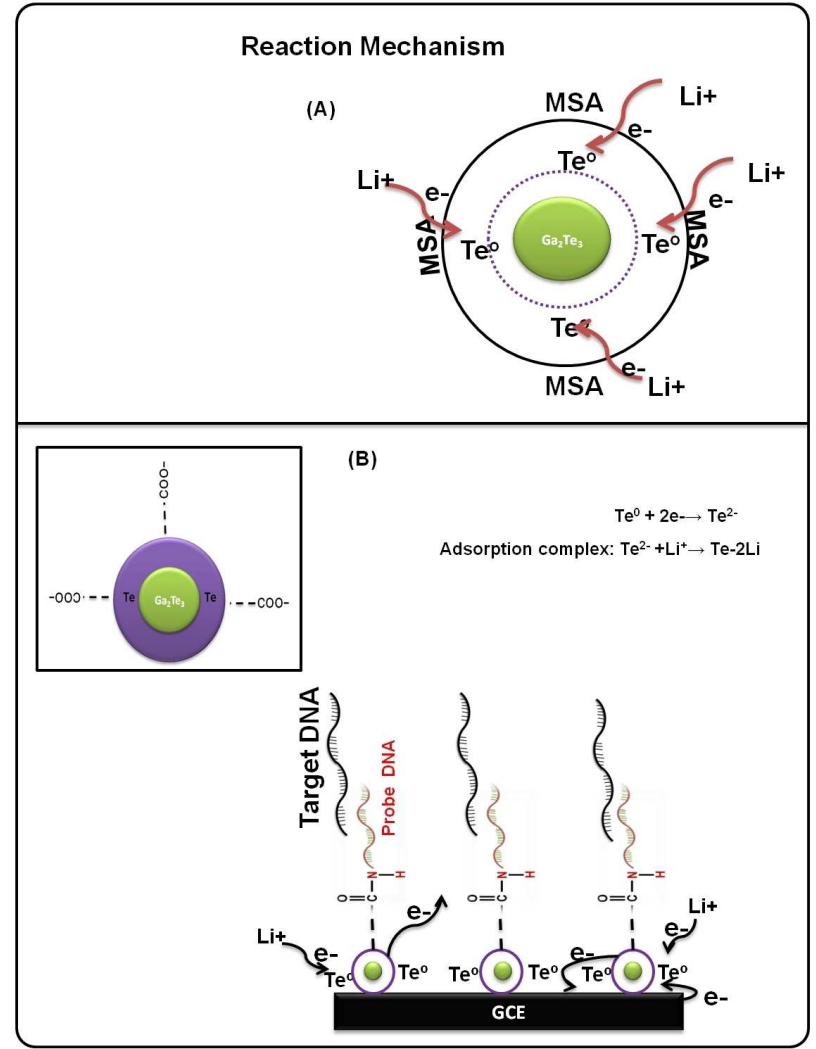

Scheme 2. Reaction mechanism of $\mathrm{GC} / 3 \mathrm{MSA} / \mathrm{Ga}_{2} \mathrm{Te}_{3} / \mathrm{dsDNA}$ with Cationic species i.e. $\mathrm{Li}^{+}$.

decrease in peak current was observed after hybridization due to big ionic radii and steric hindrance of the $\mathrm{Li}^{+}$cations.

\section{Conclusions}

The synthesis of biocompatible novel $3 \mathrm{MSA}-\mathrm{Ga}_{2} \mathrm{Te}_{3} \mathrm{QD}$ in aqueous solution has been successfully achieved with the structural morphology and optical properties of the QD successfully determined by microscopic and spectroscopic techniques. The composition of the capped QD was verified by $E D S$, in which the constituents in $\mathrm{Ga}, \mathrm{Te}, \mathrm{S}$ and $\mathrm{O}$ were observed. HRTEM was able to determine the crystallinity and particle-size of the as-synthesized QD. On the other hand, mercaptosuccinic acid used as a capping agent rendered the quantum dots biocompatible, soluble and stable. The hydrophilic nature of the 3MSA-capped QD was verified while the retention of the capping ligand on the QD surface was successfully confirmed by XPS and Raman studies, evident by vibrational stretches related to $\mathrm{C}-\mathrm{H}, \mathrm{C}=\mathrm{O},-\mathrm{SH}$ as well as $-\mathrm{O}-\mathrm{H}$ groups and oxidation states. The as-synthesized MSA-capped $\mathrm{Ga}_{2} \mathrm{Te}_{3} \mathrm{QD}$ proved to have better quantum yield in comparison with organic dye, rhodamine $6 \mathrm{G}$. Since high quantum yields are desirable in most imaging applications, the obtained data confirmed the photostability of the MSA-capped $\mathrm{Ga}_{2} \mathrm{Te}_{3} \mathrm{QD}$ and that they can be considered as an alternative to fluorescent dyes, especially in biological use. After careful investigation of 
the genosensor detection signal a possible mechanism was proposed for the first-time. The mechanism unraveled the nano-QD/DNA structure and provides insight into the underlying architecture. It was proposed that active cations are the main components responsible for genosensor detection-signal. Due to low limit of detection $\left(0.4 \mathrm{pg} \mathrm{mL}^{-1}\right)$ and low linear range (0.1-1 $\left.\mathrm{ng} \mathrm{mL}^{-1}\right)$, the results open new possibilities for DNA sensing and other biological signaling systems. The genosensor revealed significantly lower detection limit which is well below physiological limits (FDA approved) for Her2/neu detection (2$15 \mathrm{ng} \mathrm{mL}^{-1}$ ) and are comparable with reported literature values. Further, comparing the MSA-QD/DNA sensor with other DNA sensors, the genosensor is very promising and is not only recommended for Her2/neu gene but has the potential of being adapted for the sensitive detection of other transgenes for breast cancer and should also encourage future work with clinical samples.

\section{Conflict of Interest}

No competing of interest.

\section{Acknowledgement}

We acknowledge PhD bursary from DST and MINTEK NIC for Sensors and EU funding - Marie Curie IRSES FP7 SMARTCANCERSENS.

Keywords: quantum dots - genosensors - mercaptosuccinic acid $\cdot$ electroanalysis $\cdot$ mechanisms

[1] S. V. Suzete, D. Diogo, R. Jacenir, Sensors 2011, 11, 11664-11678.

[2] V. A. Jana Drbohlavova, R. Kizek, J. Hubalek, Int J.Mol. 2009, 10, 656-673.

[3] A. J. Ferancova, DNA biosensors based on nanostrucutred materials. In nanostrucutred materials in electrochemistry, (1st ed,), Wiley-VCH, Weinheim, 2008, pp. 1-40.

[4] S. M. Reiman, Rev. Mod. Phys. 2002, 74, 1285.

[5] K. Fujioka, M. Hiruoka, K. Sato, N. Manabe, R. Miyasaka, S. Hanada, A. Hoshino, R. D. Y. M. Tilley, K. Hirakuri, K. Yamamoto, Nanotechnology. 2008, 19, 415102-415109.

[6] A. Merkoci, M. Aldavert, S. Marin, S. Alegret, TrAC Trends Anal. Chem. $2005,4,341-349$.
[7] A. P. Kawasaki, Nanomedicine: Nanotechnology, Biology and Medicine. 2005, 1, 101-109.

[8] F. Ma, C. Li, C. Zhang , J. Mater. Chem. B, 2018, DOI: 10.1039/ C8TB01869C.

[9] R. Freeman, J. Girsh, I. Willner, ACS Appl. Mater. Interfaces 2013, 5, 28152834.

[10] F. Lisdat, D. Schäfer, A. Kapp, Anal. Bioanal. Chem. 2013, 405, 37393752.

[11] Y. Li, B. Ping, Z. Jin-Xian, Z. Zhen-Hua, G. Xiao, Appl. Surf. Sci. 2013, 279, 367-373.

[12] N. C. Seeman, Nature. 2003, 421, 427-431.

[13] O. Wilner, I. Willner, Chem. Rev. 2012,112, 2528-2556.

[14] W. L. Ward, K. Plakos, V. J. DeRose, Chem. Rev. 2014, 114, 4318-342.

[15] K. Li, W. Zhang, Y. Chen, Biotechnol. J. 2013, 1, 110-6.

[16] L. H. Tan, Y. Yue, N. R. Satyavolu, Y. Lu, J. Am. Chem. Soc. 2015, $137,14456-14464$.

[17] A. J. Bonham, G. Braun, I. Pavel, N. O. Reich, J. Am. Chem. Soc. 2007, 129, $14572-14573$

[18] H. Z. Zhai, N. Du, B. Chen, H. Huang, Y. Wu, D. Yang, Nanoscale Res. Lett. 2011, 6, 31-45.

[19] D. L. Erbo Ying, S. Guo, S. Dong, Small. 2006, 2, 476-480.

[20] Y. Otaki, Y. Yanadori, Y. Seki, M. Tadano, S. Kashida, J. Solid State Chem. 2009, 182, 1556-1562.

[21] Y. Otaki, Y. Yanadori, Y. Seki, K. Yamamoto, S. Kashida, Acta Mater. 2009, 57, 1392-1398.

[22] K. George, C. H.d. Groot, C. Gurnani, A. L. Hector, R. Huang, M. Jura, W. Levason, G. Reid, Phys. Procedia. 2013, 46, 142-148.

[23] U. I. Kalsoom, S. Bashir, N. Ali, Surf. Coat. Technol. 2013, 235, 297-302.

[24] M. R. Castro, J. F. Arenas, J. C. Otero, J. Raman Spectrosc. 2004, 35, 9971000.

[25] J. Creighton, In spectroscopy of Surfaces, 1st ed., Wiley, Chichester, 1988, pp. 91-101.

[26] V. I. Vinogradov, N. N. Mel'nik, P. Fernandez, L. Jing, F. T. Tela, Physics 2008, 50, 159-162.

[27] C. A. Munder, M. G. Berger, H. Liith, J. Appl. Phys. 1992, 71, 15-31.

[28] H. D. Zhernokletov, B. Brennan, M. Yakimov, V. Tokranov, Appl. Phys. Lett. 2013, 102, 131-140.

[29] X. Fuku, Anal. Methods. 2015, 7, 6114-6124.

[30] A. Larry, B. J. Ralph, Proceding of SPIE V, 2008, 7079, doi: 10.1117/ 12.796235

[31] J. Susoma, J. Lahtinen, M. Kim, J. Riikonen, AIP Adv. 2017, 7, https:// doi.org/10.1063/1.4973918.

[32] C. W. Chan, S. Nie, Science. 1998, 281, 2016.

[33] X. Chen, J. Lumin. 2002, 97, 205-211.

[34] B. Marcel, Science. 1998, 281, $2013-2016$.

[35] A. Darr, J. Mater. Sci. 2009, 20, 33-44.

[36] P. Bulpitt, J. Biomed. Mater. Res. 1999, 47, 152-169.

[37] J. V. Staros, Anal. Biochem. 1986, 156, 220-226.

[38] H. Chai, P. Miao, Anal. Chem. 2019, 91, 4953.

[39] L. A. Currie, Anal. Chim. Acta. 1999, 391, 127-134.

[40] B. Zhu, J. Travas-Sejdic, Analyst. 2018, 143, 687-694.

[41] Y. Liu, A. Kannegulla, B. Wu, L. J. Cheng, ACS Appl. Mater. Interfaces. 2018, 10, 18524-18531.

Manuscript received: December 13, 2019

Revised manuscript received: January 19, 2020

Accepted manuscript online: January 20, 2020 